\title{
ESTRUTURA DE MADEIRA PARA COBERTURA DE AVIÁRIOS NO ESTADO DA PARAÍBA ${ }^{1}$
}

\author{
Marluce Araújo de Azevedo² \& José Wallace Barbosa do Nascimento ${ }^{3}$
}

\begin{abstract}
RESUMO
Este trabalho apresenta o cálculo estrutural de cobertura com treliça do tipo "Howe", utilizando-se as madeiras roxinho (Peltogyne sp., Leguminosae) e maçaranduba (Manilkara sp., Sapotaceae) disponíveis no mercado de Campina Grande, Paraíba, e visa a execução de projeto de estrutura para aviário, considerando-se as recomendações da norma técnica brasileira NBR 7190/1997 e duas situações de galpão: aviário com oitões em alvenaria e ventilação artificial e aviário com oitões abertos e túnel de vento no sentido longitudinal, ambas com $12 \mathrm{~m}$ de vão e $125 \mathrm{~m}$ de comprimento. Devido à globalização da economia, a escolha do projeto arquitetônico se deu em função do tipo de exploração, dos parâmetros de conforto térmico, manejo, custo e uso racional da madeira. Os resultados obtidos indicam que a estrutura formada por treliça composta de banzos com seções transversais simples de 7,5 x 12,5 cm, diagonais com seções transversais simples de 7,5 x 10,0 cm e montantes com seções transversais duplas de $3,5 \times 12,5 \mathrm{~cm}$, terças com seções transversais de $7,5 \times 15 \mathrm{~cm}$, contraventamento tendo seção transversal de 7,5 x 12,5 cm e espaçamento entre treliças de $2,72 \mathrm{~m}$, apresenta o menor consumo de madeira por metro quadrado de área coberta e, conseqüentemente, o menor custo.
\end{abstract}

Palavras-chave: cobertura, estrutura de madeira, aviário

\section{TIMBER STRUCTURES FOR POULTRY SHED ROOFING IN THE STATE OF PARAÍBA, BRAZIL}

\begin{abstract}
This paper presents the design for roofing using the "Howe" type truss and the "roxinho" (Peltogyne sp., Leguminosae) and "maçaranduba" (Manilkara sp., Sapotaceae) species that are available in the Campina Grande, Paraíba market, for the construction of the structural design of chicken sheds, considering the recommendations set forth by the NBR 7190/1997 technical code. Two different chicken sheds are described herein: the first shed has brick walls and artificial ventilation, and the second has open walls and a longitudinal wind tunnel. Both sheds are $12 \mathrm{~m}$ wide and $125 \mathrm{~m}$ long. Due to globalization of the economy, the choice of architectural design was based considering parameters of comfort, handling, cost and rational use of wood. The types of roofing structure are composed of trusses comprising chords with single $7.5 \times 12.5 \mathrm{~cm}$ cross sections, diagonals with single $7.5 \times 10.0 \mathrm{~cm}$ cross sections and struts with double $3.5 \times 12.5 \mathrm{~cm}$ cross sections, and purlins with $7.5 \times 15 \mathrm{~cm}$ cross sections. Both sheds have $7.5 \times 12.5 \mathrm{~cm}$ cross section bracing and $2.72 \mathrm{~m}$ spacing between trusses. The results obtained indicate that this type of structure uses less wood per square meter of covered area and costs less.
\end{abstract}

Key words: roofing, timber structure, poultry shed

\footnotetext{
${ }^{1}$ Parte da Dissertação de Mestrado defendida pelo primeiro autor na UFPB, Campina Grande, PB

${ }^{2}$ Prof $^{\mathrm{a}}$ M. Sc. do Departamento de Engenharia Agrícola, Universidade Federal da Paraíba, Av. Aprígio Veloso 882, CP 10.087, CEP 58109 - 970, Campina Grande, PB. Fone: (083) 310 1318, Fax: (083) 310 1185. E-mail: marluce@ deag.ufpb.br

${ }^{3}$ Prof. Dr. do Departamento de Engenharia Agrícola, Universidade Federal da Paraíba, Campina Grande, PB, E-mail:wallace@deag.ufpb.br
} 


\section{INTRODUÇÃO}

A avicultura no Estado da Paraíba cresceu significativamente nos últimos anos, aumentando de 5,8 milhões para 6,2 milhões de aves entre 1985 e 1996, segundo o Censo Agropecuário. A evolução decorreu da expansão da demanda dos principais núcleos urbanos (Censo Agropecuário, 1999).

Ao extraordinário progresso científico verificado na avicultura contrapõe-se a pouca atenção que se deu, até recentemente, às características das construções projetadas para o alojamento das aves. Desta maneira, a avicultura contemporânea passa a avaliar o ambiente de confinamento das aves como aspecto determinante na obtenção de maiores benefícios resultantes da produtividade.

Dentre os fatores ambientais que afetam o conforto das aves, a temperatura, a umidade relativa do ar, a velocidade do ar e a radiação solar, são consideradas mais importantes para as aves. Esses fatores comprometem sua função vital mais essencial, que é a manutenção da própria homeotermia. Se estas condições estão próximo das ideais, a probabilidade de se obter alta produtividade é grande (Tinôco, 1996).

No Brasil, os abrigos para aves são ainda, em sua grande maioria, instalações abertas e sem ambiente controlado. Por razões econômicas de curto prazo ou mesmo por desconhecimento, pouca atenção se tem dado às fases de planejamento e concepção arquitetônica compatíveis com a realidade climática de cada região (Tinôco, 1997).

Os fatores ambientais do Estado da Paraíba, a competitividade e a globalização da economia e o desenvolvimento da avicultura de corte na mesorregião do Agreste Paraibano, motivaram a elaboração de projetos de estrutura de madeira para a cobertura de aviários, considerandose sistema artificial de condicionamento térmico (Azevedo, 1999).

As estruturas em pórticos premoldados de concreto, embora competitivas com as de madeira, são fabricadas com inclinação insuficiente para cobertura com telha de barro e escoamento das águas pluviais. Os sistemas construtivos adotados para os galpões, na maioria das granjas, comprometem as condições de conforto térmico e de manejo, além de limitar o vão, em $10 \mathrm{~m}$.

O objetivo do presente trabalho é apresentar projeto de estrutura treliçada em madeira, tipo "Howe", para cobertura de aviários nos padrões atuais de $12 \mathrm{~m}$ de vão e $125 \mathrm{~m}$ de comprimento, considerando-se duas situações de aviários: uma com oitões em alvenaria e ventilação artificial lateral e a outra com oitões abertos e túnel de vento no sentido longitudinal.

\section{MATERIAL E MÉTODOS}

\section{Material}

Adotaram-se as madeiras nativas roxinho (Peltogyne sp., Leguminosae) e maçaranduba (Manilkara sp., Sapotaceae) cujas características, segundo a metodologia, são: $\mathrm{f}_{\mathrm{cok}}=61,2$ $\mathrm{MPa} ; \mathrm{E}_{\mathrm{c} 0 \mathrm{~m}}=20.097 \mathrm{MPa}$ e $\rho_{\text {aparente }}=852 \mathrm{~kg} \mathrm{~m}^{-3} ; \mathrm{f}_{\mathrm{cok}}=58,4 \mathrm{MPa}$; $\mathrm{E}_{\mathrm{c} 0, \mathrm{~m}}=20.790 \mathrm{MPa}$ e $\rho_{\text {aparente }}=1008 \mathrm{~kg} \mathrm{~m}^{-3}$, respectivamente.

$\mathrm{f}_{\mathrm{cok}}$ - resistência característica da compressão paralela das fibras

$\mathrm{E}_{\mathrm{c} 0 \mathrm{~m}}$ - modelo de elasticidade paralela às fibras da madeira

$\rho^{\mathrm{co}, \mathrm{m}}$ - densidade

\section{Caracterização das espécies adotadas}

A caracterização das madeiras foi realizada segundo as recomendações da norma NBR 7190/1997 para madeira serrada de espécies usuais, a partir dos ensaios de compressão paralela às fibras, teor de umidade e densidade aparente, utilizando-se os métodos especificados no Anexo $\mathrm{B}$ da referida norma.

Os valores das resistências $\mathrm{f}_{1}, \mathrm{f}_{2}, \ldots, \mathrm{f}_{6}$ obtidos para cada espécie de madeira, no ensaio de compressão paralela às fibras, foram corrigidos para a umidade padrão de referência de $12 \%$, de acordo com a recomendação da norma NBR 7190/1997, pela expressão:

$$
f_{12}=f_{U \%}\left[1+\frac{3(U \%-12)}{100}\right]
$$

$\mathrm{f}_{12} \quad$ - resistência a compressão paralela às fibras a $12 \%$ de umidade

$\mathrm{f}_{U \%}$ - resistência a compressão paralela às fibras a $U \%$ de umidade

U - umidade do corpo-de-prova.

Com a tabulação dos dados referentes a compressão paralela às fibras, a $12 \%$ de umidade, a análise estatística foi realizada através do software ASSISTAT (Silva, 1996) para delineamento inteiramente casualizado e o valor característico da resistência $f_{c 0 . k}$ foi estimado, conforme a NBR 7190/1997, por:

$$
f_{c 0 k}=\left[2 \frac{f_{1}+f_{2}+\ldots+f_{\frac{n}{2}-1}}{\frac{n}{2}-1}\right] * 1,1
$$

n - número de corpos-de-prova ensaiados (para caracterização simplificada, $\mathrm{n} \geq 6$ )

Os resultados obtidos foram colocados em ordem crescente $\mathrm{f}_{1} \leq \mathrm{f}_{2} \leq \ldots \leq \mathrm{f}_{6}$, não se tomando, para $\mathrm{f}_{\mathrm{c} 0 . \mathrm{k}}$, valor inferior a $\mathrm{f}_{1}$ nem a 0,7 do valor médio.

Os valores da rigidez $\mathrm{E}_{1}, \mathrm{E}_{2}, \ldots, \mathrm{E}_{6}$ obtidos para cada espécie de madeira foram corrigidos para a umidade padrão, pela expressão:

$$
E_{12}=E_{U \%}\left[1+\frac{2(U \%-12)}{100}\right]
$$

$E_{12}$ - módulo de elasticidade a compressão paralela às fibras a $12 \%$ de umidade

$\mathrm{E}_{\mathrm{U} \%}$ - módulo de elasticidade a compressão paralela às fibras a U\% de umidade.

O valor do módulo de elasticidade paralelo às fibras é representado pelo valor médio $\mathrm{E}_{\mathrm{c} 0, \mathrm{~m}}$.

\section{Dimensionamento da estrutura de madeira}

Para o dimensionamento da estrutura foram consideradas as seguintes hipóteses de cálculo:

- planta da edificação: $12 \mathrm{~m}$ de largura por $125 \mathrm{~m}$ de comprimento (Figura 1) com duas situações a considerar: 1) oitões em alvenaria e ventilação artificial lateral

2) oitões abertos (treliças nas extremidades) com túnel de vento no sentido longitudinal

- paredes laterais em ambas as situações são executadas em tela com malha de 1/2" (12,5 mm) e cortina de polietileno

- telhado com duas águas, simétrico e inclinação de $25^{\circ}$

- pé-direito do aviário igual a 4,20 m 


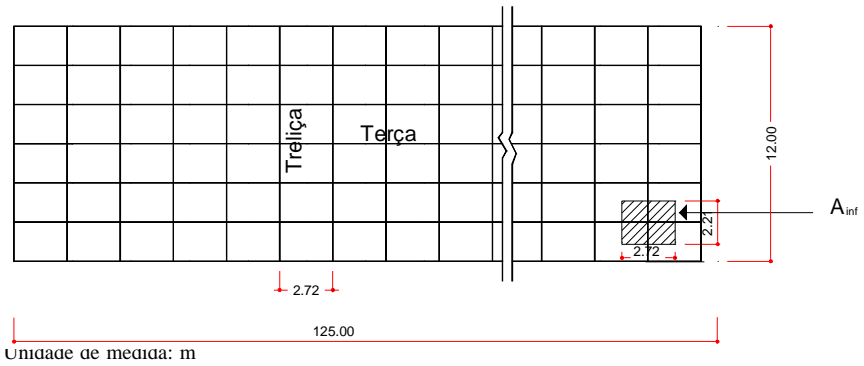

Figura 1. Esquema das treliças e terças

- cobertura com telha de barro, tipo canal

- peso médio da telha, na região, é da ordem de 35 da $\mathrm{N} \mathrm{m}^{-2}$

- treliças tipo "Howe", com a geometria indicada na Figura

2, com seções transversais simples nos banzos e diagonais e seção dupla nos montantes

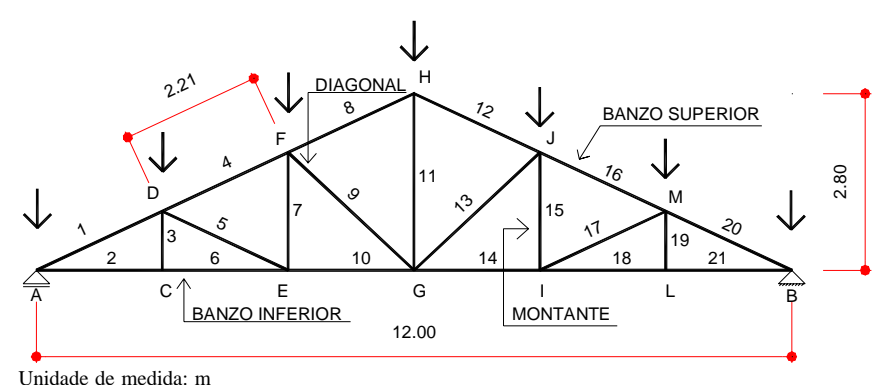

Figura 2. Geometria das treliças para as duas situações de aviários

- os nós das treliças são considerados rótulas ideais

- esquema estático da treliça: estrutura isostática, com apoio rotulado fixo e um apoio rotulado móvel

- os carregamentos externos são transferidos para a treliça na forma de cargas concentradas aplicadas nos nós

- consideração apenas de esforços axiais (tração e compressão) nas treliças

- ligações através de parafusos passantes

- seções nominais de vigas disponíveis no mercado: $7,5 \times 7,5 \mathrm{~cm}, 7,5 \times 10 \mathrm{~cm}, 7,5 \times 12,5 \mathrm{~cm}, 7,5 \times 15 \mathrm{~cm} \mathrm{e}$ $7,5 \times 20 \mathrm{~cm}$

- comprimento máximo das vigas de madeira é de 7,00 m

- terças com seções transversais nominais das vigas e esquema estático bi-apoiado

- contraventamento horizontal colocado nas extremidades do aviário, em ambas as situações estudadas, na parte central para galpão com oitões em alvenaria (coincidente com o vão de contraventamento vertical) e a cada três vãos em caso de aviário com oitões abertos (também coincidente com o vão das treliças verticais) como indica a Figura 3A

- contraventamento vertical considerado a cada três vãos, para os montantes números 3, 11 e 19, conforme mostra a Figura 3B (os vãos sem treliças estão interligados aos contraventados, por intermédio de correntes)

- seções nominais de caibros e ripas: 5 x $7 \mathrm{~cm}$ (caibrão) e $1,5 \times 4 \mathrm{~cm}$ (ripa)

- material trabalhando na fase elástica linear, ou seja, na faixa de validade de Lei de Hooke em todos os elementos estruturais

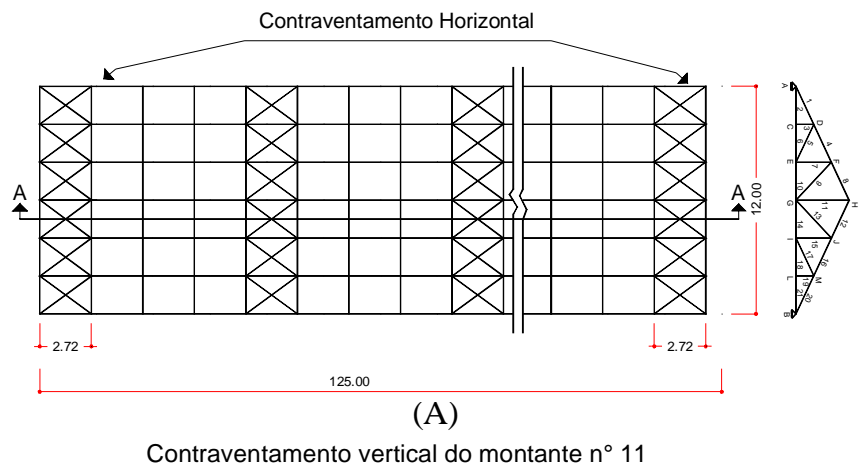

Vista A - A

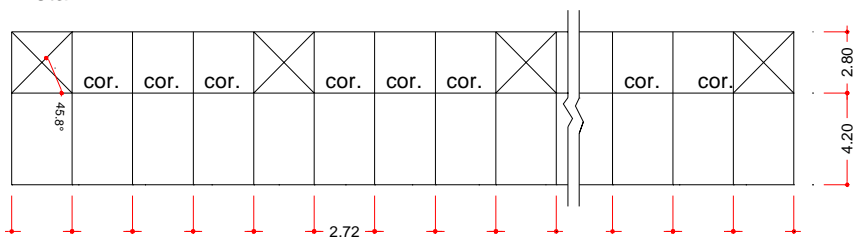

(B)

Unidade de medida: $\mathrm{m}$

cor $=$ corrente

Figura 3. Arranjos dos contraventamentos contraventamento horizontal (b) contraventamento vertical do montante $\mathrm{n}^{\mathrm{o}} 11$

- módulo de elasticidade longitudinal $\left(\mathrm{E}_{\mathrm{c} 0}\right)$ constante para toda a peça

O desenvolvimento dos projetos foi realizado de acordo com as prescrições das normas brasileiras NBR 7190/1997 - Projeto de Estruturas de Madeira, NBR 6120/1982 - Cargas para o Cálculo de Estruturas de Edificações, NBR 6123/1988 - Forças devidas ao Vento em Edificações. Para o dimensionamento das treliças, terças, ligações e contraventamento, foram utilizadas planilhas eletrônicas do Programa EXCEL e, para os desenhos, o Programa AutoCAD.

\section{RESULTADOS E DISCUSSÃO}

\section{Dimensões finais}

De acordo com as propriedades da madeira, as hipóteses de cálculo, os documentos normativos mencionados e otimização de cada projeto, foram obtidas, através do dimensionamento, as seções transversais dos elementos estruturais que compõem as treliças, terças e contraventamento, de modo que as seções transversais adotadas para os elementos estruturais são as seguintes:

a) treliças com espaçamento de $2,72 \mathrm{~m}$

- banzos $\rightarrow$ seção simples 7,5 x 12,5 cm indicada na Figura 4A

- diagonais $\rightarrow$ seção simples $7,5 \times 10 \mathrm{~cm}$, conforme mostra a Figura 4B

- montantes $\rightarrow$ seção dupla 3,5 x $12,5 \mathrm{~cm}$, como indica a Figura 4C

b) terças

7 peças com seção transversal simples 7,5 x $15 \mathrm{~cm}$

c) contraventamento

peças com seção transversal simples 7,5 x 12,5 cm.

Para a otimização dos projetos, foram fixados, inicialmente, a geometria da treliça, as seções transversais das barras da treliça as terças, os caibros, as ripas e o espaçamento entre treliças. As planilhas eletrônicas, para dimensionamento de treliça, terça e 


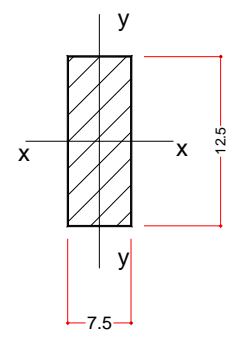

(A)

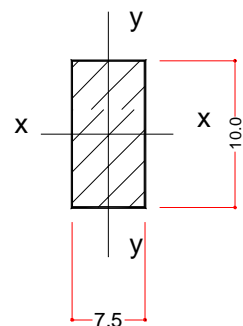

(B)

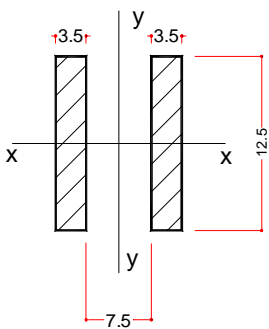

(C)
Unidade de medida: $\mathrm{cm}$

Figura 4. Seção transversal das barras da treliça: (A) banzos superior e inferior (B) diagonais $(C)$ montantes

ligação, implementaram todas as verificações pertinentes. $\mathrm{Na}$ hipótese das seções transversais serem aprovadas, aumentouse o espaçamento entre as treliças e repetiu-se o processo até se obter o espaçamento máximo (visando-se menor consumo de madeira por metro quadrado de área coberta); quando a seção transversal das terças ou as ligações foram reprovados, para determinado espaçamento, diminuiu-se a distância entre as treliças e realizaram-se novos dimensionamentos da estrutura considerada, até se chegar à aprovação; assim, todas as composições possíveis das seções nominais disponíveis no mercado, para a geometria de treliça adotada, foram verificadas e a composição apresentada conduziu ao menor consumo de madeira por metro quadrado de área coberta.

A seção transversal adotada nos contraventamentos, horizontal e vertical, foi de 7,5 x 12,5 cm, conforme dimensionamento realizado para o esquema apresentado na Figura 3. A disposição dos contraventamentos teve por base: redução dos custos da estrutura, a não inversão de esforços (devido ao vento) no tipo de construção estudada e o número reduzido de pessoas envolvidas nas atividades do galpão (em decorrência da automação dos comedouros e bebedouros); além disso, para a situação de aviário com oitões abertos, onde o contraventamento horizontal é mais crítico, a reação deste, nas extremidades, é transferida às colunas, que são pontos fixos.

\section{Consumo de material}

Adotando-se o procedimento de Pinheiro (1996) o consumo de madeira por unidade de área coberta para as situações estudadas está mostrado na Tabela 1. Comparando-se os resultados da situação de galpão com oitões abertos e galpão com oitões em alvenaria, percebe-se que são praticamente iguais e a diferença decorre do contraventamento horizontal que, na primeira situação, possui espaçamento menor.

Tabela 1. Consumo de madeira por unidade de área coberta

\begin{tabular}{lcccccc}
\hline $\begin{array}{l}\text { Situação do } \\
\text { Aviário }\end{array}$ & \multicolumn{3}{c}{ Volume de Madeira } & & \multicolumn{2}{c}{ Consumo de Madeira } \\
\cline { 2 - 4 }$\left(\mathrm{m}^{3}\right)$ & $\begin{array}{c}\text { Treliça } \\
\left(\mathrm{m}^{3}\right)\end{array}$ & $\begin{array}{c}\text { Caibros/ripas } \\
\left(\mathrm{m}^{3}\right)\end{array}$ & $\begin{array}{c}\text { Contravent. } \\
\left(\mathrm{m}^{3} \mathrm{~m}^{-2}\right)\end{array}$ & $\begin{array}{c}\text { Total } \\
\left(\mathrm{m}^{3} \mathrm{~m}^{-2}\right)\end{array}$ \\
\hline $\begin{array}{l}\text { Oitões em } \\
\text { alvenaria }\end{array}$ & 0,384 & 0,217 & 0,387 & & 0,003 & 0,993 \\
Oitões abertos & 0,384 & 0,217 & 0,387 & & 0,005 & 0,995 \\
\hline
\end{tabular}

\section{Ligações}

A adoção de todos os parafusos com diâmetro de $10 \mathrm{~mm}$ se deu devido aos aspectos construtivos e às indicações de Calil Júnior (1998) de que o diâmetro de parafusos utilizados nas ligações das treliças não deve ser inferior a $10 \mathrm{~mm}$. No dimensionamento das ligações foram usados os esforços internos, considerando-se a totalidade dos esforços devido à ação do vento, conforme item 5.5.8 da NBR 7190/97. Os valores apresentados na segunda coluna da Tabela 2 estão assim distribuídos nos nós da Figura 2:

a. cobrejuntas para os nós A e B (ligação entre banzos) dez parafusos passantes em ambas as situações de aviário, conforme mostra a Figura 5
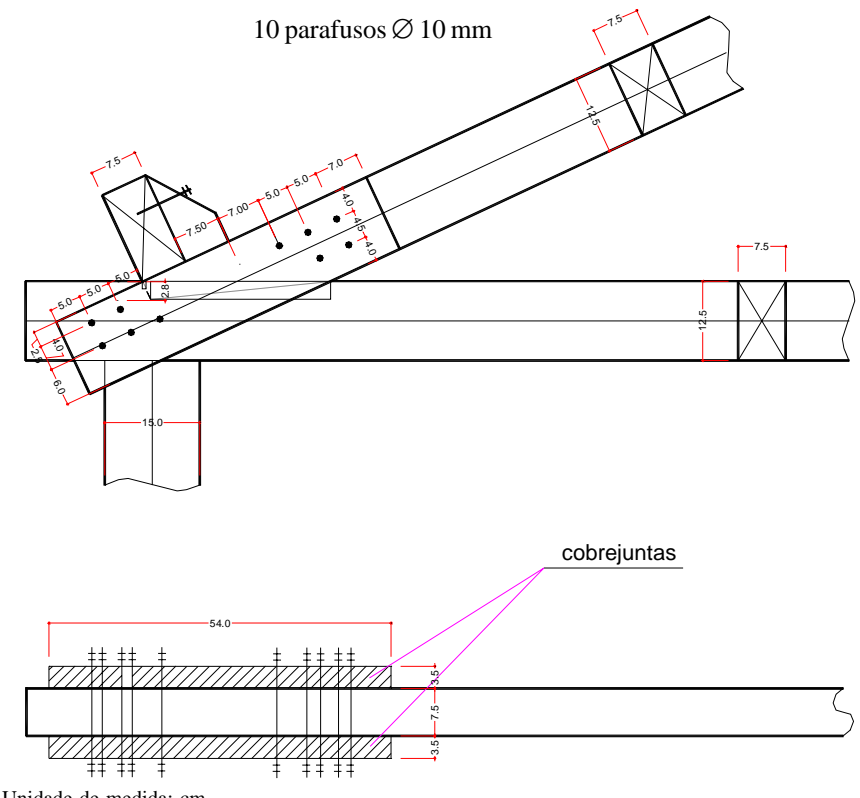

Unidade de medida: $\mathrm{cm}$

Figura 5. Ligações dos banzos (nós A e B)

b. ligação das barras dos nós $\mathrm{D}, \mathrm{M}, \mathrm{F}$ e J - dois parafusos passantes ligando o montante ao banzo superior e um parafuso de rosca soberba na ligação entalhada entre a diagonal e o banzo superior, como indica a Figura 6

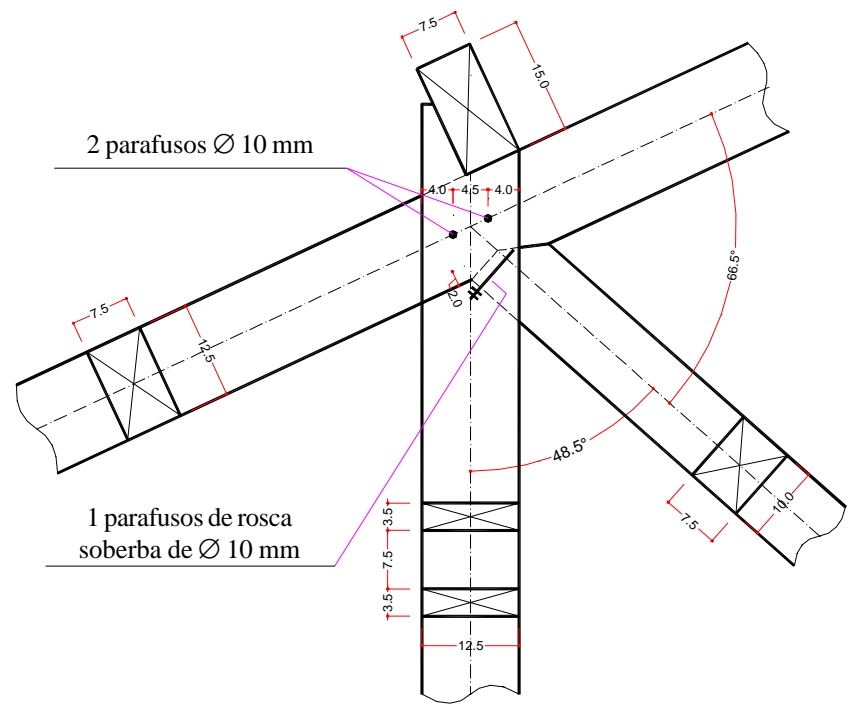

Unidade de medida: $\mathrm{cm}$

Figura 6. Ligações das barras dos nós F e J

c. ligação das barras dos nós $\mathrm{C}$ e $\mathrm{L}$ - dois parafusos passantes unindo o montante ao banzo inferior

d. ligação das barras do nó $\mathrm{G}$ - três parafusos passantes ligando o montante ao banzo inferior e dois parafusos de rosca 
soberba unindo as diagonais ao banzo inferior, de acordo com a Figura 7

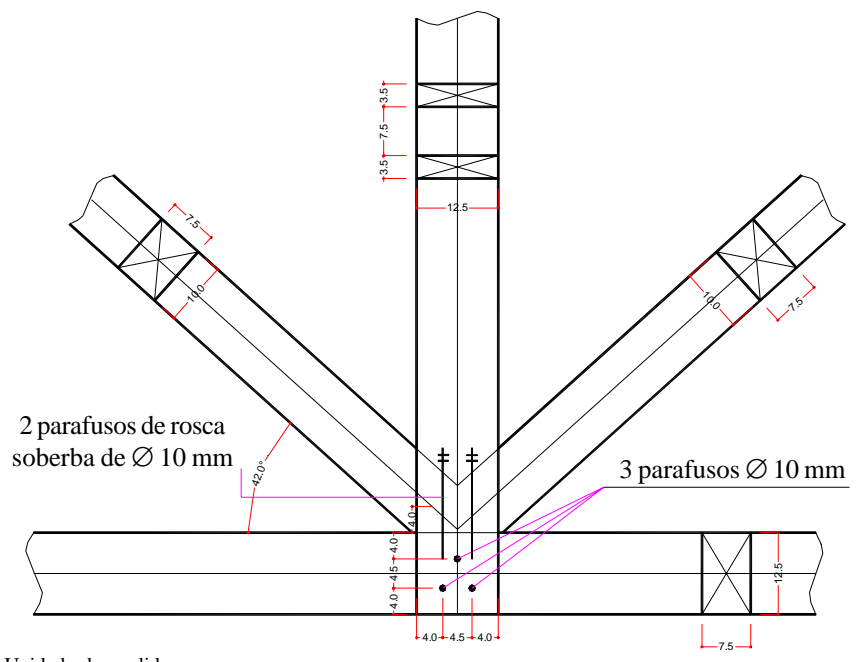

Unidade de medida: $\mathrm{cm}$

Figura 7. Ligações das barras do nó $\mathrm{G}$

e. ligação das barras dos nós E e I - dois parafusos passantes ligando o montante ao banzo inferior e um parafuso de rosca soberba na ligação entalhada entre a diagonal e o banzo inferior

f. ligação das barras dos nó H (montante funciona como cobrejunta) - três parafusos passantes ligando cada parte do banzo superior, ou seja, seis parafusos no total da ligação, conforme apresenta a Figura 8

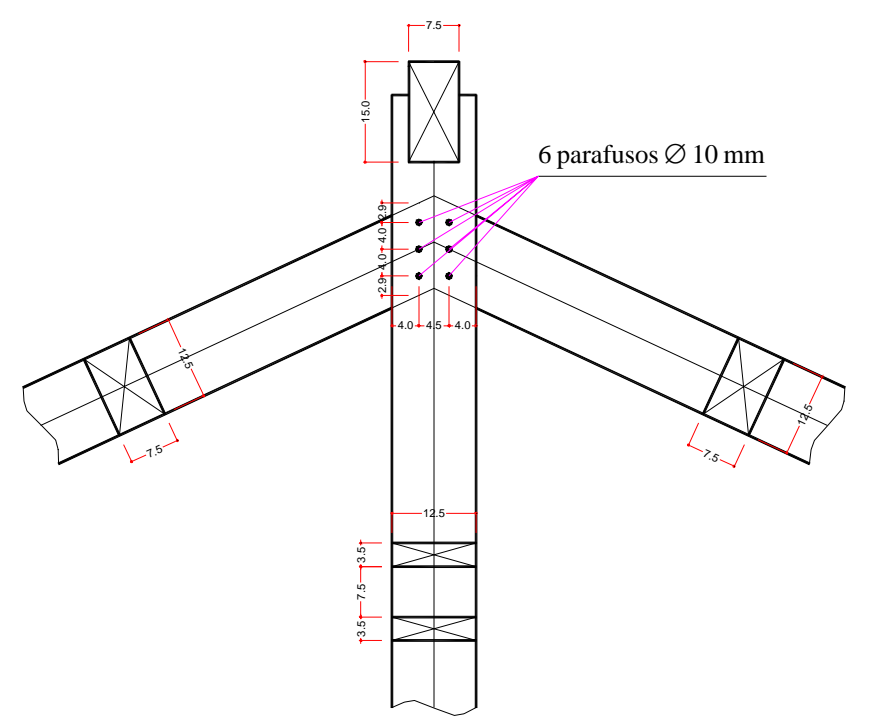

Unidade de medida: $\mathrm{cm}$

Figura 8. Ligações das barras do nó H

g. emendas dos banzos superior e inferior (uma para cada banzo) - seis parafusos passantes em cada ligação.

Os itens a, b, c, ..., f referem-se às duas situações de galpões com estrutura de roxinho. Não foram apresentadas as Figuras das ligações entre as barras dos nós C, L, E e I, porque se trata de ligações simples. Pela mesma razão, não se apresentaram as emendas dos banzos, embora seja oportuno ressaltar que a emenda do banzo superior, para aviário com oitões abertos, tem oito parafusos passantes. Quanto às ligações dos nós $\mathrm{D}$ e $\mathrm{M}$, são semelhantes às ligações das barras dos nós $\mathrm{F}$ e J, mudando apenas o ângulo entre a diagonal e o banzo superior.

As ligações para a estrutura de maçaranduba, correspondentes à situação de galpão com oitões em alvenaria, seguem as descrições e ilustrações vistas nos itens a, b, ..., f. A emenda do banzo superior, neste caso, tem oito parafusos passantes e a do banzo inferior é idêntica à realizada com roxinho. Para a situação de galpão com oitões abertos, adotam-se as soluções apresentadas nos itens a, b, ..., e. A ligação das barras do nó $\mathrm{H}$ possui sete parafusos passantes e, quanto às emendas dos banzos superior e inferior, cada uma apresenta oito parafusos.

Os valores apresentados na Tabela 2 registra a quantidade de parafusos, o diâmetro utilizado e o consumo de parafusos em relação ao volume de madeira empregado nas estruturas principais (treliças) e secundárias (terças, caibros e ripas).

Tabela 2. Consumo de parafusos por $\mathrm{m}^{3}$ de madeiras

\begin{tabular}{lccc}
\hline $\begin{array}{c}\text { Situação do } \\
\text { aviário }\end{array}$ & $\begin{array}{c}\text { Quantidade de } \\
\text { parafusos/treliça }\end{array}$ & $\begin{array}{c}\text { Diâmetro } \\
(\mathrm{mm})\end{array}$ & $\begin{array}{c}\text { Consumo de } \\
\text { parafusos } / \mathrm{m}^{3}\end{array}$ \\
\hline $\begin{array}{c}\text { A. Roxinho } \\
\text { Oitões em } \\
\text { alvenaria }\end{array}$ & 65 & 10,0 & 66 \\
Oitões abertos & 67 & 10,0 & 68 \\
\hline $\begin{array}{l}\text { B. Maçaranduba } \\
\text { Oitões em } \\
\text { alvenaria }\end{array}$ & 67 & 10,0 & 68 \\
Oitões abertos & 70 & 10,0 & 71 \\
\hline
\end{tabular}

Comparando-se os resultados da última coluna da Tabela 2 , verifica-se que as situações de aviário com estrutura de maçaranduba necessitam de maior consumo de parafusos, em razão do peso próprio da estrutura construída com esta madeira ser maior.

\section{Custo de material}

A Tabela 3 mostra o custo por metro quadrado, de material, para o preço de mercado local praticado em setembro do corrente ano.

Tabela 3. Custo por metro quadrado para cobertura com madeira roxinho e maçaranduba

\begin{tabular}{lcccc}
\hline $\begin{array}{l}\text { Situação do } \\
\text { Aviário }\end{array}$ & $\begin{array}{c}\text { Estrutura } \\
\left(\mathrm{R} \$ \mathrm{~m}^{-2}\right)\end{array}$ & $\begin{array}{c}\text { Contrav. } \\
\left(\mathrm{R} \$ \mathrm{~m}^{-2}\right)\end{array}$ & $\begin{array}{c}\text { Parafusos } \\
\left(\mathrm{R} \$ \mathrm{~m}^{-2}\right)\end{array}$ & $\begin{array}{c}\text { Total } \\
\left(\mathrm{R} \$ \mathrm{~m}^{-2}\right)\end{array}$ \\
\hline $\begin{array}{l}\text { A. Roxinho } \\
\begin{array}{c}\text { Oitões em } \\
\text { alvenaria }\end{array}\end{array}$ & 13,60 & 1,44 & 1,05 & 16,09 \\
$\begin{array}{c}\text { Oitões abertos } \\
\text { B. Maçaranduba }\end{array}$ & 13,60 & 2,40 & 1,08 & 17,08 \\
$\begin{array}{c}\text { Oitões em } \\
\text { alvenaria }\end{array}$ & 13,60 & 1,44 & 1,08 & 16,12 \\
Oitões abertos & 13,60 & 2,40 & 1,13 & 17,13 \\
\hline
\end{tabular}

Analisando-se o custo total $\mathrm{m}^{-2}$, praticamente não há diferença de preço entre as duas madeiras quando se considera uma mesma situação de aviário. A pequena diferença dos resultados decorre do custo dos parafusos, 
conforme se verifica na penúltima coluna da Tabela 3; por outro lado, comparando-se as duas situações estudadas, a cobertura de aviários com oitões abertos apresenta custo mais elevado, em virtude do contraventamento horizontal.

\section{CONCLUSÕES}

A partir dos resultados do projeto de estrutura de madeira para cobertura, com treliça tipo "Howe" e as duas situações de aviários consideradas, conclui-se que:

1. A otimização dos projetos indica que a estrutura composta por treliças, espaçadas $2,72 \mathrm{~m}$, com banzos de seções transversais simples de $7,5 \times 12,5 \mathrm{~cm}$, diagonais $7,5 \times 10 \mathrm{~cm}$, montantes com seções duplas de $3,5 \times 12,5 \mathrm{~cm}$, terças 7,5 x 15 $\mathrm{cm}$ e contraventamentos de $7,5 \times 12,5 \mathrm{~cm}$, apresenta menor consumo de madeira $/ \mathrm{m}^{2}$ de área coberta e pode ser construída em ambas as situações estudadas.

2. A estrutura para cobertura de aviário, em cada situação, independe da madeira ser roxinho ou maçaranduba, embora a estrutura seja mais leve com roxinho.

3. A estrutura de madeira para aviário com oitões abertos é mais onerosa, em virtude do maior consumo de material exigido no contraventamento horizontal.

4. A cobertura de aviário com oitões em alvenaria é viável para as regiões do Estado com maior disponibilidade d'água, considerando-se ser normal a utilização da ventilação lateral associada à nebulização, e a situação de aviário com oitões abertos é apropriada às localidades com escassez de chuvas.

5. Terças com seções transversais simples e ligações limitam o espaçamento entre treliças.

\section{REFERÊNCIAS BIBLIOGRÁFICAS}

ABNT (Rio de Janeiro, RJ). NBR - 6120, Cargas para o cálculo de estruturas de edificações, 1982.

ABNT (Rio de Janeiro, RJ). NBR - 6123, Forças devidas ao vento em edificações, 1988.

ABNT (Rio de Janeiro, RJ). NBR - 7190, Projeto de estruturas de madeira, 1997.

AZEVEDO, M.A. Estrutura de madeira para cobertura de aviários no Estado da Paraíba. Campina Grande: Universidade Federal da Paraíba, 1999. 91p. Dissertação Mestrado.

CALIL JÚNIOR, C. Estruturas de madeira. São Carlos: Escola de Engenharia de São Carlos, Universidade de São Paulo, 1998. 102p.

CENSO AGROPECUÁRIO. Anuário 99 da Avicultura Industrial, São Paulo, Ano 89, n.1062, p. 76, jan. 1999.

PINHEIRO, R.V. Emprego da madeira do gênero Pinus na construção de estruturas de cobertura. São Carlos: Escola de Engenharia de São Carlos, Universidade de São Paulo, 1996. 163p. Dissertação Mestrado.

SILVA, F.A.S. The ASSISTAT software: Statistical assistance. In: INTERNATIONAL CONFERENCE ONCOMPUTERS IN AGRICULTURE, 6, Cancun, 1996. Proceedings... Cancun: American Society of Agricultural Engineers, 1996. p.294-298. TINÔCO, I.F.F. Produção avícola em clima tropical. Viçosa: Departamento de Engenharia Agrícola, Universidade Federal da Viçosa, 1997.37p.

TINÔCO, I.F.F. Efeito de diferentes sistemas de acondicionamento de ambiente e níveis de energia metabolizável na dieta sobre o desempenho de matrizes de frangos de corte, em condições de verão e outono. Belo Horizonte: Escola de Veterinária, Universidade Federal de Minas Gerais. 1996. 173p. Tese Doutorado. 